\title{
Effect of Management Practices on Soil Microstructure and Surface Microrelief
}

\author{
R. Garcia Moreno, ${ }^{1}$ T. Burykin, ${ }^{2}$ M. C. Diaz Alvarez, ${ }^{1}$ and J. W. Crawford ${ }^{2}$ \\ ${ }^{1}$ Centre for Studies and Research on Agricultural and Environmental Risk Management (CEIGRAM), School of Agricultural \\ Engineering, Polytechnic University of Madrid, Ciudad Universitaria s.n., 28040 madrid, Spain \\ ${ }^{2}$ Faculty of Agriculture, Food and Natural Resources, Australian Technology Park, University of Sydney, \\ Eveleigh, Sydney, NSW 2015, Australia
}

Correspondence should be addressed to R. Garcia Moreno, rosario.garciam@udc.es

Received 1 December 2011; Revised 8 March 2012; Accepted 9 March 2012

Academic Editor: Philip White

Copyright ( $) 2012$ R. Garcia Moreno et al. This is an open access article distributed under the Creative Commons Attribution License, which permits unrestricted use, distribution, and reproduction in any medium, provided the original work is properly cited.

\begin{abstract}
Soil surface roughness (SSR) and porosity were evaluated from soils located in two farms belonging to the Plant Breeding Institute of the University of Sidney. The sites differ in their soil management practices; the first site (PBI) was strip-tilled during early fall (May 2010), and the second site (JBP) was under power harrowed tillage at the end of July 2010. Both sites were sampled in midAugust. At each location, SSR was measured for three $1 \mathrm{~m}^{2}$ subplots using shadow analysis. To evaluate porosity and aggregation, soil samples were scanned using X-ray computed tomography with $5 \mu \mathrm{m}$ resolution. The results show a strong negative correlation between SSR and porosity, $20.13 \%$ SSR and $41.38 \%$ porosity at PBI versus $42.00 \%$ SSR and $18.35 \%$ porosity at JBP. However, soil images show that when soil surface roughness is higher due to conservation and soil management practices, the processes of macroaggregation and structural porosity are enhanced. Further research must be conducted on SSR and porosity in different types of soils, as they provide complementary information on the evaluation of soil erosion susceptibility.
\end{abstract}

\section{Introduction}

Soil surface roughness (SSR), which describes the microvariations in soil elevations primarily resulting from tillage practices and textural porosity, is one of the major factors affecting wind and water erosion [1-4]. SSR is a direct indicator of the degradation of soil microstructure, which is mainly due to a loss of physical, chemical, and biological properties $[1,2,5]$. In this case, SSR is closely related to erosion, which is the primary cause for the loss of soil structure and organic matter, and it leads to a decrease in soil productivity and reduced fauna diversity $[4,6]$.

SSR promotes soil biota activity, which plays an important role in the rehabilitation of sealed soil surfaces and the restructuring of soils, particularly after compaction events [7]. SSR is mainly affected by management practices and, depending on the techniques used, SSR can increase the number and variability of microorganisms through the improvement of soil porosity and flow water in the vadose zone [8]. The increase in microorganism activity is very important in most biogeochemical cycles within soils because it improves the physical and biological state of the soil $[4,9,10]$. Thus, tillage influences the development of different types of microorganisms. Techniques that conserve pore systems tend to enhance the activity of microorganisms and conserve the biota that are beneficial to the development of crops $[7,11,12]$.

However, the study of soil porosity and its relation to other properties is complicated because soil is one of the most complex materials on all scales [12, 13].

By defining soil structure as the arrangement of particles and associated pores in soils, ranging from nanometres to centimetres, we can demonstrate the biological influence on the stabilisation of aggregates at macro-to-micro scales and their relationship with soil surface processes [14]. This assumption was proposed by Oades [14], who found that 
degradation of cultivated land starts with the breakdown of aggregates from larger structures and the corresponding pores, which control drainage and aeration $(>30 \mu \mathrm{m})$.

Soil porosity includes textural porosity and structural porosity. Textural porosity is also known as matrix, intraaggregate, or intrapedal porosity. It is produced by the voids between primary mineral particles. Structural porosity, also called interaggregate or interpedal porosity, is produced by the pores between aggregates or soil blocks. The morphology and interconnection of structural porosity is closely related to the shape, size, and stability of aggregates and blocks, and it is generally also related to the soil genesis and type of soil use. Knowledge of the pore size distribution allows the evaluation of connectivity and soil flow properties $[9,10,15]$.

Dexter [9] found that management factors, such as tillage, cropping, and compaction, have great influence on structural porosity and showed that soils with poorer physical quality produce more clods. There is a strong relation between small aggregates $(<8 \mathrm{~mm})$ and large aggregates $(>32 \mathrm{~mm})$ because from an agronomic point of view, tillage must create fine aggregates to obtain optimal plant emergence. From this point of view, large aggregates or clods have no agronomic significance and may create problems for soil management, causing soil aggregation to be very important in preventing soil erosion [1].

The aggregate hierarchy proposed by Hadas [16] and reviewed by Dexter [17] represents one of the most frequently applied theories due to its simplicity. The lowest hierarchical order is the combination of single mineral particles, such as clay plates, into a basic type of compound particle (e.g., a domain of clay plates). The next hierarchical order is formed by larger compound particles, such as clusters of domains. Once these clusters come together to form microaggregates, they enter the next hierarchical order, and so on. We find greater compaction and higher homogeneous properties for orders of decreasing size. The existence of different orders of aggregates depends on soil properties [16].

The stability of micro- and macro-aggregates also presents different properties. Although macroaggregate stability is positively correlated to different types of structures of organic matter, microaggregate stability fails to correlate to any type of organic matter $[15,18]$. In some cases, humic substances may play an important role in the cohesion between clay particles through links with polyvalent cations $[15,19]$. However, studies presenting soils with different pedogenesis have shown that microaggregate stability is mainly associated with soil mineralogy [18].

High-quality soil systems assure that physical, chemical, and biological properties are appropriated for soil conservation, thus avoiding soil degradation in a production system. Thus, any management practice that increases soil aggregation improves the structure of soils and permits the development of textural soil, which positively influences the function of soil ecosystems $[20,21]$. This is reinforced by Hati et al. [22], showing that one of the main elements to assure soil fertility is the maintenance of optimum soil physical conditions through the applications of conservation practices. Hati et al. [22] corroborated that the decline of organic matter content in soil is associated with the physical degradation of soil.

Six et al. [23] corroborated the former theory. They found that tillage operations strongly influence the organic matter associated with aggregates because tillage operations increase the aggregate formation and the associated organic matter leads to the stabilisation of soil structure by increasing the structural porosity. In fact, a lack of tillage leads to an increase in particulate organic matter related to microand macro-aggregates compared to conventional tillage operations.

Kravchenko et al. [19] studied the organic matter of soils handled by different tillage systems over 15 years and found that soils managed with no tillage conserved the highest organic matters. When plots were conventionally tilled, the plots covered with residual vegetal matter conserved more organic matter than bare soils. The authors demonstrated that conservation techniques are able to increase the soil organic matter. Soil texture also plays an important role in the conservation of organic matter. In general, soils with higher clay contents have a positive correlation with the organic matter content, although the mineralisation of the organic matter is increased in more coarsely textured soils [24].

Therefore, research has shown that the net productivity of cultivated soils comes from the addition of numerous physical, chemical, and biological processes, which occur on the micrometre-to-metre scale, where soil porosity plays a very important role in facilitating the processes $[25,26]$. Observations of soil in thin sections are an essential tool for evaluating biota activity in relation to the description and quantification of soil porosity, its potential impact on soil formation and conservation, its influence on soil connectivity $[3,27]$ and associated degradation processes $[19,24]$.

Microstructures are used to determine most of the processes in soils $[12,21,28]$. Computer tomography analysis and three-dimensional images of soil microstructures have been crucial to understanding the role of organic matter, its relation to soil aggregate stability and its influence on soil porosity. Macro- and micro-pores seem to play a very important role in organic matter degradation and conservation through aggregate stabilisation and porosity distribution $[11,12,21,25,28]$.

Progress in computer tomography (CT) technology offers the possibility of imaging the nondestructive threedimensional structure of soils at resolutions relevant to the interactions between physical, chemical, and biological soil properties $[3,26,29]$. Unfortunately, current scanners and image processing software are not able to resolve microbial cells; however, they can reproduce organic matter and its distribution through the pore system, which can be an indirect indicator of microbial activity [3].

Several authors $[26,29]$ have found that the morphology of the soil pore distribution is an important factor in understanding soil processes and formation at the small scale. X-ray computed tomography (CT) has been used to study aggregate stability in relation to pore architecture as a means of investigating microbial activity. These authors 
concluded that stability, rather than morphology, of pores plays an important role in the formation of aggregates at the microstructure scale.

Soil surface roughness has also been related to texture, porosity and organic matter [30]; however, its relation with the formation of aggregates has been poorly studied.

Based on previous studies $[1,2,12,13,28]$, the aim of the present study is to evaluate the influence of soil management practices on soil porosity and soil surface roughness as well as the relationship between both indicators. Soil cores were studied using X-ray computed tomography (CT) to visualise soil pore spaces in three dimensions, and soil surface roughness was measured using shadow analysis. The evaluation is suited to integrated SSR characterisation related to the estimation of soil pore spaces and the visualisation of the architecture of aggregates as a function of soil management practices.

\section{Materials and Methods}

2.1. Experimental Sites. The field experiments were conducted at two sites belonging to the Breeding Plant Institute of the University of Sidney under different management practices (Figure 1): one at the main facilities of the experimental farm of the Plant Breeding Institute (PBI) and the second at John B. Pye (JBP) Farm (Figure 2). Both sites are located $65 \mathrm{~km}$ southwest of Sidney, Australia, $34^{\circ} 00^{\prime} 51^{\prime \prime} \mathrm{S}$ $150^{\circ} 40^{\prime} 49^{\prime \prime} \mathrm{E}$ and are characterised as red dermosol with a clay loamy texture according to the Australian Soil Classification [31].

The main difference between the two sites was the management practices (Table 1). The sites were chosen based on their differences in crop management in order to relate conservation practices to soil surface roughness and microstructure. The first site (PBI) was strip-tilled beginning on May 2010 during early fall. The site was characterised as having bare soils, being highly eroded, and having no cover protection. The JBP plots were characterised by conservation management practices. The JBP soils were power harrowed to $5 \mathrm{~cm}$ at the end of July and covered with cereal crop remains incorporated into the soil and prepared for sowing cereals. The images and samples were taken on August 13. Surface images of both soils at the time of sampling are presented in Figures 2 and 3.

Soil surface roughness and microstructure were measured for samples from three randomly chosen $1 \mathrm{~m}^{2}$ subplots within each site using shadow analysis and a tomography scan. The samples for porosity measurement were taken at the soil surface level. Sidney Observatory Hill recorded $249.6 \mathrm{~mm}$ for Fall 2010, below the historical average of $397.1 \mathrm{~mm}$. The regional value recorded for the New South Wales region was $141.8 \mathrm{~mm}$, slightly below the historical average of $142.7 \mathrm{~mm}$ [32].

2.2. Soil Surface Roughness Data. Soil surface roughness was measured at three $1 \mathrm{~m}^{2}$ subplots from each site. For each subplot, three images were taken from the south, north, and west. Thus, nine images from each site were compared and



FIGURE 1: Sampling locations: the blue dot indicates PBI, and the red dot indicates JBP.



(a)

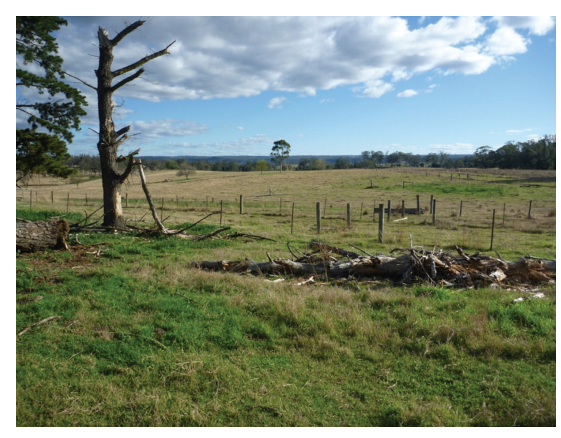

(b)

Figure 2: Experimental sites at PBI (a) and JBP (b).

measured for soil surface roughness. The images taken from the south at each location are shown in Figures 2 and 3.

Shadow analysis is based on the assumption that the lengths of shadows cast at a given angle in bright daylight are proportional to soil microrelief $[1,2]$. The images were captured with a Panasonic DMC-FT2 digital camera at a resolution of 14.50 MP.

All photos were taken at a solar angle of $40^{\circ}$ to preclude any possibility of sunlight-induced differences during the same day. The test fields were close enough to ensure that the angle of incident light was the same. This angle was verified before images were taken. 
TABLE 1: Differences in management practices for the experimental sites.

\begin{tabular}{llccc}
\hline Location & Soil texture & Management & Coverage & Date of sampling \\
\hline PBI & Clay loam & Strip tillage (last week of July) & Bare soil & August 13, 2010 \\
JBP & Clay loam & Power harrow (first week of May) & Straw cover & \\
\hline
\end{tabular}
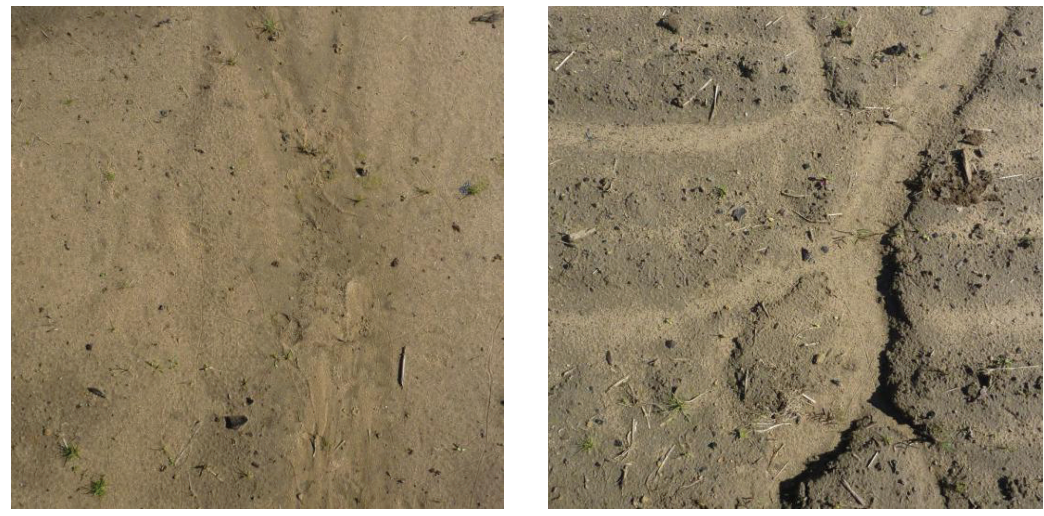

(a)
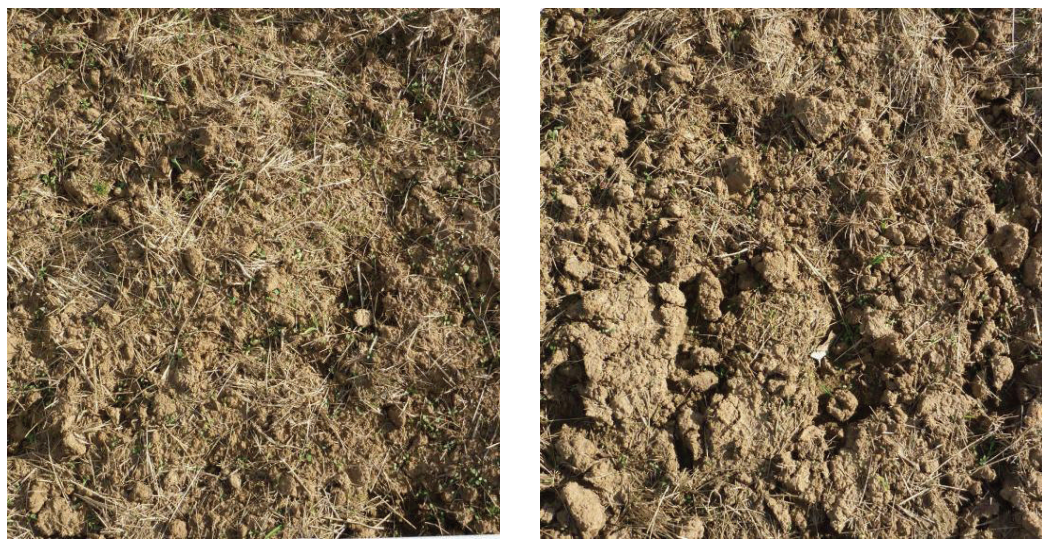

(b)
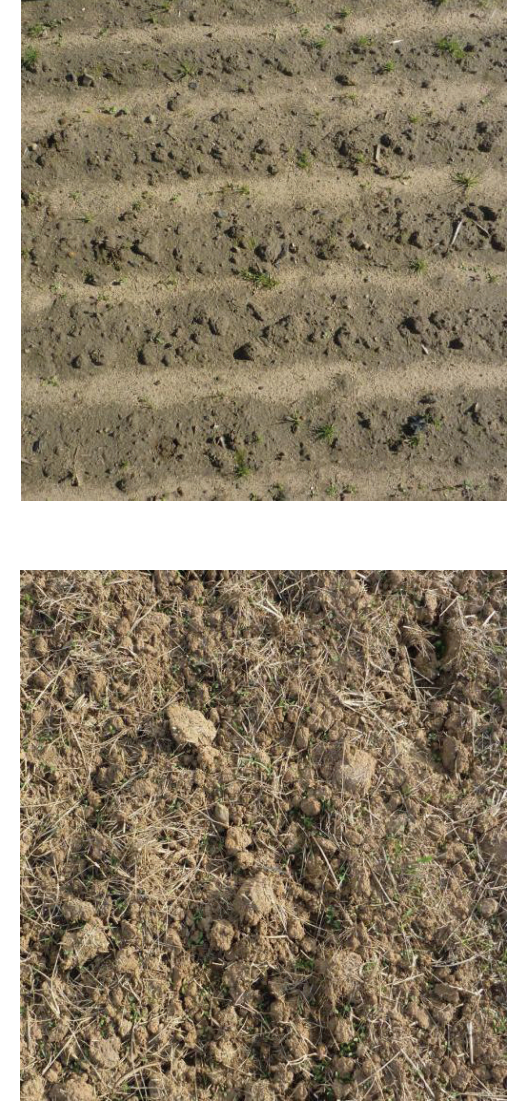

Figure 3: Soil surface roughness (SSR) images of PBI plots ( 1 cob, 2 cob, and 3 cob on (a) L-R) and JBP plots ( 1 jbp, 2 jbp, and 3 jbp on (b) L-R). Each measurement was taken three times.

A frame of $1 \mathrm{~m}^{2}$ was used to take the images and assure that the same area was chosen for each subplot reading. The camera was set on a Slik tripod to photograph the entire $1.0 \mathrm{~m}^{2}$ area in a single frame and to assure that the camera lens was placed parallel to the soil surface at a height of $1.65 \mathrm{~m}$. The focal angle and the distance from the lens to the ground were constant throughout to ensure that the resolution would be the same in all photos. The shadows cast by the soil microrelief were analysed with byte map histograms using Corel Draw Photo Paint (Corel Corporation 1992-1996) software. After identification on the histogram, the shaded points were converted to a black surface against a white background. The shadow index was then computed as the percentage of blackout of the total number of pixels. The results from each subplot were an average measurement of the three-directional images. Pore network and voxel-based soil porosity were evaluated using computed tomography.
2.3. Computed Tomography Measurements. The images for tomography measurements were taken using an XRADIA micro-XCT-400 that belongs to the Australian Centre for microscopy and microanalysis, University of Sidney (Figure 4). In addition to the quantification of porosity, this technique allows visualisation of the pore distribution and shape as well as connectivity and aggregation.

The samples used in the CT scanner were taken from the soil surface at the six field locations. The height of each sample was $4 \mathrm{~mm}$, and the diameter was $2 \mathrm{~mm}$. The samples were fixed to the structure of the scan without any further preparation. Each sample was taken from the subplot at the same location where the soil surface roughness was measured. The resolution of the images was $5 \mu \mathrm{m}$, and a threshold algorithm was applied to convert the greyscale images to binary images, with black corresponding to the pore space and white and grey to soil matrix, including organic matter. 
TABLE 2: Soil surface roughness (SSR) and porosity at the soil surface, expressed in percentages. The values in parentheses are the standard deviations.

\begin{tabular}{|c|c|c|c|}
\hline Location & Sample ID & Porosity (\%) & SSR $(\%)$ \\
\hline \multirow{13}{*}{ PBI } & $1 \mathrm{~N}$ & & $14.6(2.36)$ \\
\hline & $1 \mathrm{~W}$ & & $14.08(1.41)$ \\
\hline & $1 \mathrm{~S}$ & & $15.50(0.01)$ \\
\hline & total 1 & 38.07 & $14.25(1.41)$ \\
\hline & $2 \mathrm{~N}$ & & $22.22(0.16)$ \\
\hline & $2 \mathrm{~W}$ & & $21.78(0.84)$ \\
\hline & $2 \mathrm{~S}$ & & $25.58(1.06)$ \\
\hline & total 2 & 42.92 & $23.19(1.96)$ \\
\hline & $3 \mathrm{~N}$ & & $21.32(0.36)$ \\
\hline & $3 \mathrm{~W}$ & & $25.46(0.63)$ \\
\hline & $3 S$ & & $22.10(0.15)$ \\
\hline & total 3 & 45.01 & $22.96(1.82)$ \\
\hline & Total & $42.00(3.56)$ & $20.13(5.10)$ \\
\hline \multirow{13}{*}{ JBP } & $1 \mathrm{~N}$ & & $44.60(1.13)$ \\
\hline & $1 \mathrm{~W}$ & & $43.50(1.12)$ \\
\hline & $1 \mathrm{~S}$ & & $42.68(0.00)$ \\
\hline & total 1 & 17.55 & $43.60(1.02)$ \\
\hline & $2 \mathrm{~N}$ & & $39.20(2.38)$ \\
\hline & $2 \mathrm{~W}$ & & $42.27(0.52)$ \\
\hline & $2 \mathrm{~S}$ & & $39.68(0.31)$ \\
\hline & total 2 & 18.23 & $40.39(1.84)$ \\
\hline & $3 \mathrm{~N}$ & & $40.83(2.35)$ \\
\hline & $3 \mathrm{~W}$ & & $41.58(3.51)$ \\
\hline & $3 \mathrm{~S}$ & & $38.08(0.48)$ \\
\hline & Total 3 & 19.28 & $40.16(2.15)$ \\
\hline & Total & $18.35(0.87)$ & $41.38(1.92)$ \\
\hline
\end{tabular}

This equipment functioned as a high-resolution, nondestructive 3D X-ray imaging system with a spatial resolution of $<1 \mu$ and $0.56 \mu \mathrm{m}$ pixel size. This technique provides the full three-dimensional structure of soil samples with minimal resolution dependence on the size and its preparation. The images were then evaluated using image analysis software, which allowed the exploration of soil porosity and the visualisation of soil microstructure.

The image processing began with reduction in greyscale to reduce brightness. A sigma filter was applied to reduce noise and preserve structure within images. The smoothed images were segmented to produce binary images for the analysis of porosity and interconnectivity. For calculation, the images were subjected to greyscale segmentation using different threshold values. The percentage porosity was calculated as a percentage of black space, and the differences between two locations were statistically compared using analysis of variance.

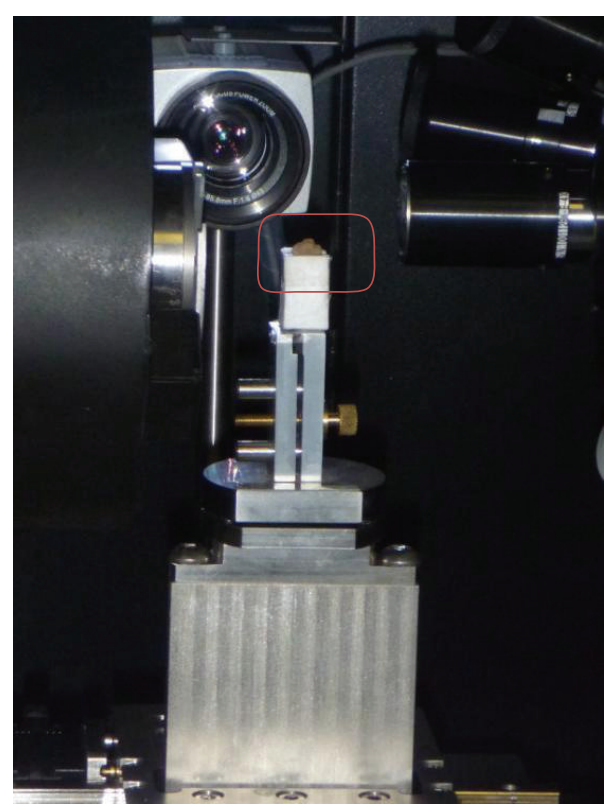

Figure 4: CT Scanner (Xradia CTX 400) with sample.

\section{Results}

Table 2 shows the results of SSR for each plot and from each direction expressed in percentage of shadows. There are no significant differences in measurements for the same subplot at sampling positions ( $\mathrm{N}, \mathrm{S}$, and $\mathrm{W})$. For this reason, only the averages of each subplot are considered, allowing direct comparison with the porosity percentages. Results from different directions are in agreement with results from previous studies at different geographical locations, where this technique was validated with other well-tested methods $[1,2]$.

Comparing the results in Table 2 with the resulting images of SSR patterns for both sites (Figure 2) shows that the numerical results express the roughness differently from the images of each subplot.

Based on both sources of roughness measurement, the SSR results from PBI facilities were lower because they showed a higher degree of erosion than the plots at JBP, and the PBI plots were not tilled since the beginning of fall. Additionally, the degree of erosion of the PBI subplots varies, mainly due to rainfall. The images of the first subplot show the highest degree of erosion, followed by the second and third subplots. The last two subplots show very similar results for the percentage of shadows. At the second subplot, the erosion is primarily related to the ridges created by rainfall erosion, and at the last subplot, the remaining erosion is created by tillage operations and the increase in oriented soil surface roughness.

In contrast, the results from JBP subplots give higher, more consistent levels of roughness. The percentages of shadows obtained for JBP follow those for PBI. These values are due to the type and later time of tillage and conservational practices, including the addition of grass residuals to reduce erosion. 
TABLE 3: Analyses of variance and covariance for SSR and porosity percentages.

(a)

Statistics of regression

\begin{tabular}{lc}
\hline Multiple correlation & 0.993902605 \\
Coefficient R^2 & 0.987842388 \\
Adjusted $R^{\wedge} 2$ & 0.983789851 \\
Standard error & 1.790239741 \\
Observations & 5 \\
\hline
\end{tabular}

(b)

\begin{tabular}{lcccc}
\hline & Degrees of freedom & SS & $\begin{array}{c}\text { Average of the } \\
\text { squared deviations }\end{array}$ & F Critique value \\
\hline Regression & 1 & 781.237405 & 781.237405 & 243.7589899 \\
Residual & 3 & 9.61487499 & 3.20495833 & 0.000571022 \\
Total & 4 & 790.85228 & & \\
Covariance & & -120.3479056 & & \\
Corr. Coef. & & -0.904242715 & & \\
\hline
\end{tabular}

The soil surface roughness was compared to the porosities to study their potential relation and to observe how different management approaches influence the inner structures of soil, particularly porosity and its influence on erosion.

The resulting inner structures found in the sampling aggregates from different sites and subplots are shown in Figure 6. These images represent the complete aggregate and a visualisation of the inner core of samples.

The images of samples from the JBP site present a stronger degree of aggregation than samples from PBI (Figures 5 and 6). The degree of cementation is high in clumps from JBP, indicating that these soils are less susceptible to erosion than soils with a low degree of aggregation, such as the PBI samples. Because both soils have the same texture, the higher degree of aggregation in the PBI samples seems to be produced by a higher presence of organic matter and organisms. The higher presence of macroaggregates and greater SSR percentages (Figures 5 and 6) is related to tillage practices and residual organic matter used as cover. Thus, the porosity at JBP is distributed in well-organised channels. These results are based on the literature reviews and indicate that the observed porosity is mainly related to structural porosity with the organisation of interaggregates [16, 17].

The percentages of porosity found in both experimental sites (Table 2) show that the porosity at PBI is almost twice that calculated for JBP. However, examination of the inner structure (Figure 6) shows that PBI samples lack aggregation and are more susceptible to erosion. Therefore, PBI has a higher percentage of textural porosity, where particles form intraaggregates with cohesion mainly associated with soil mineralogy and where microaggregates are the dominant hierarchical order [18]. This result is supported by the lowest percentage of SSR showing less resistance to erosion $[1,2]$.

\section{Discussion}

Comparing the results obtained for SSR with porosity values of the experimental plots shows that plots with higher percentages of SSR have lower percentages of porosity, as is the case for the PBI samples.

The regression analysis was used to compare SSR and porosity, indicating a negative correlation with $R^{2}=0.99$, significant at $P<0.0015$ (Figure 7; Table 3).

The resulting relation between the two parameters corroborates the erosion properties of both sites. Soils from PBI show low aggregation, high porosity, very low microrelief of the soil surface, and low resistance to erosion, most of which is induced by rainfall, as indicated by the presence of ridges. The $3 \mathrm{D}$ images show that the high porosity is mainly due to textural porosity with a low degree of aggregation, and the absence of vegetal coverture and low percentage of SSR make the soil highly sensitive to erosion.

However, the images of subplots from JBP show that soil management practices have increased the SSR associated with the formation of macroaggregates and the presence of interaggregates $[16,17,19]$. Structural porosity seems to prevail over textural porosity here. These properties give the JBP plots a high degree of stabilisation, with the formation of macroaggregates due to the presence of organic matter and possibly microorganisms (Figures 5 and 6) [15, 19], and a lower susceptibility to erosion than PBI [19].

The observed differences in structures and SSR are related to the soil tillage practices and the existence of grass residues that protect the soil surface from erosion, enhancing the inner structure and well-organised soil interconnectivity of the JBP plots [20-22].

In comparison, the highest soil surface roughness among PBI plots is closely related to the lack of soil structure 

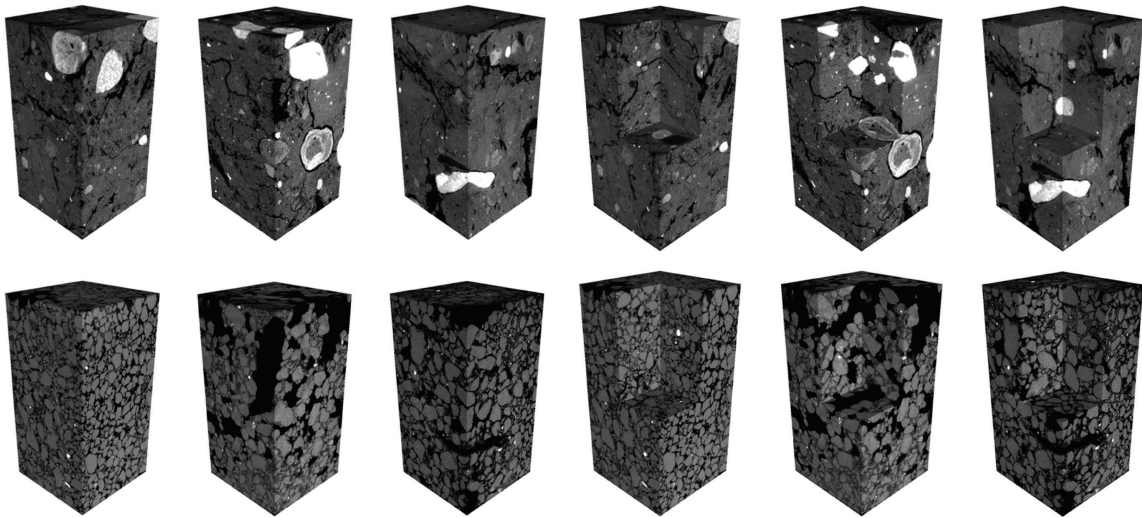

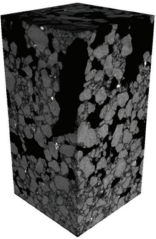

(a)
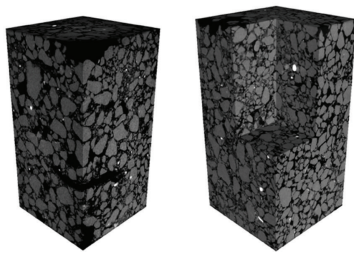

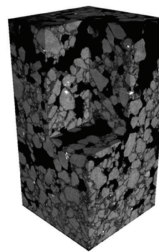

(b)

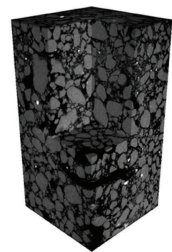

FIGURE 5: Scanned soil samples. PBI samples are on the bottom and JBP samples are on the top. A) complete scanned sample, B) internal view of scanned sample.
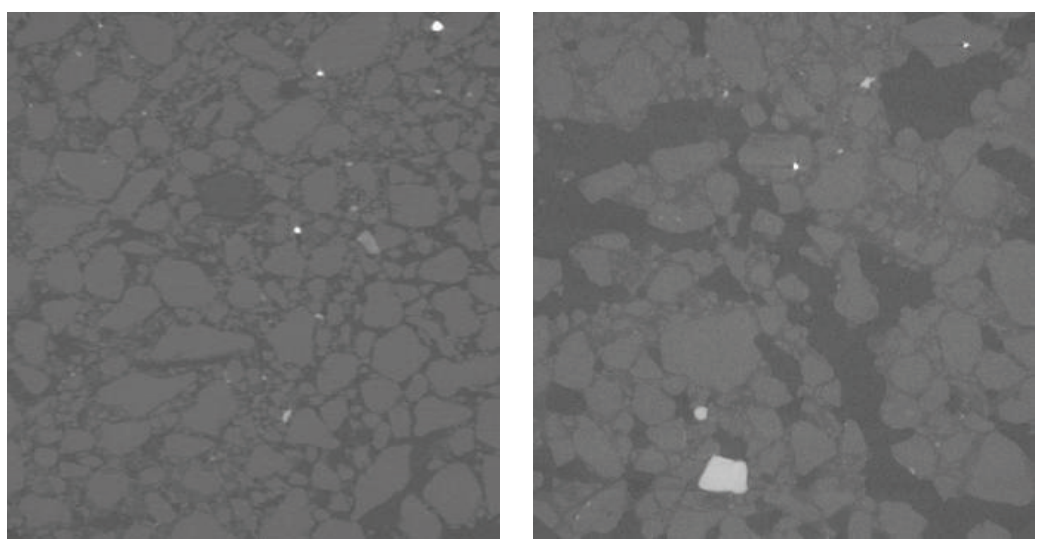

(a)
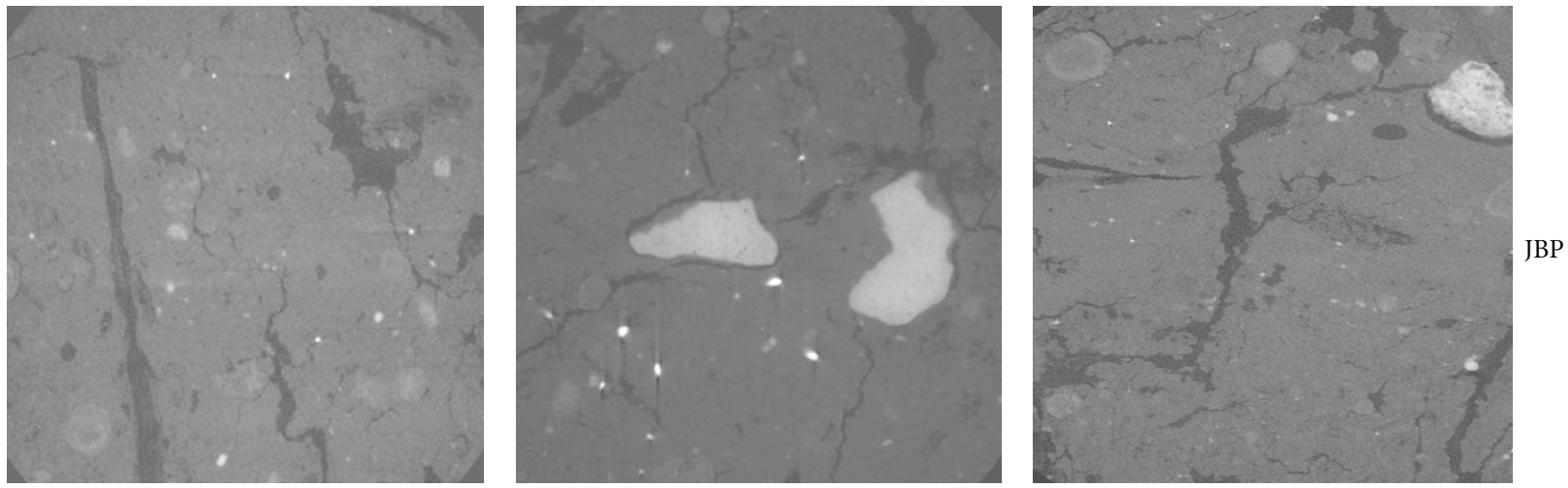

(b)

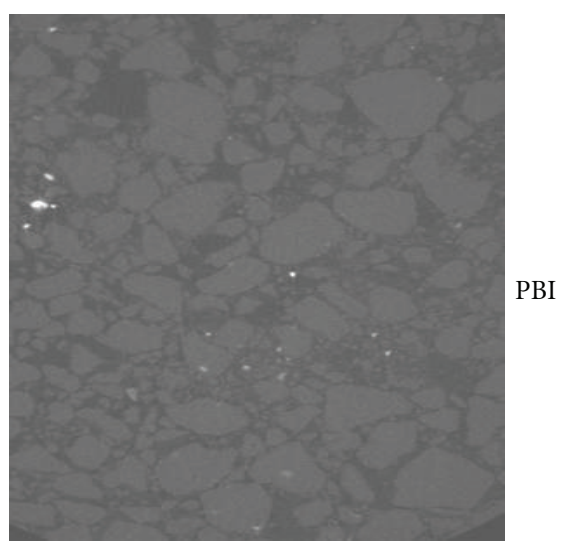

FIgURE 6: Internal distribution of porosity. PBI is shown at the top and JBP is shown at the bottom. For each site, samples 1,2 and 3 are ordered L-R.

due to the high erosion rate caused by the lack of soil surface protection and the soil management practices, that is, the exposure of bare surface to water erosion, destroying the inner aggregation and interconnectivity of the soil [19].

\section{Conclusion}

Based on the results obtained in this study, SSR is closely related to soil aggregation, structural porosity, and the presence of macroaggregates. The high porosity of PBI 


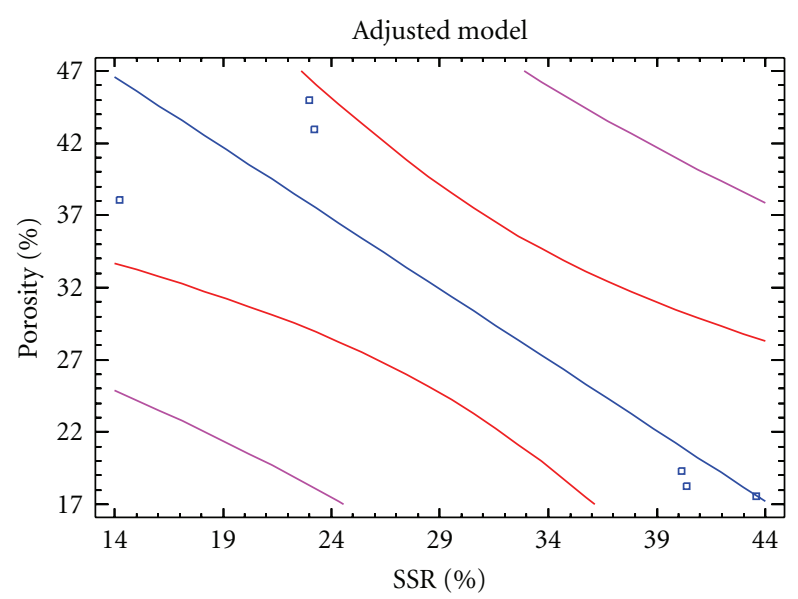

Figure 7: Regression analysis of porosity (\%) versus SSR (\%).

samples with low SSR percentages indicates high disturbance and the lack of macroaggregation of soil, whereas images of JBP samples with higher SSR values and lower porosities indicate a higher presence of macroaggregates and a higher degree of stabilisation.

Both parameters indicate that the implementation of management conservation practices, particularly conservation tillage practices and use of residual coverage on the soil surface, prevent erosion and enhance soil macroaggregation and stabilisation due to organic matter and organisms being less susceptible to soil surface erosion.

Therefore, the SSR values are increased as soil is tilled as a conservation practice, and the microstructures indicate aggregation. In this sense, the high percentage of SSR produces lower erosion rates in soil, promoting the formation of macroaggregates. Here, soil porosity and soil SSR have a negative correlation, with an $R^{2}$ value of $99.9 \%$.

From these results, it can be concluded that the study of SSR and the observation of the inner structures of soil are complementary and can be used to evaluate the influence of soil management practices on soil erosion susceptibility.

However, further research on the comparison of soil types and different management practices must be performed to confirm the findings of this study relating soil microstructures and SSR as well as to complement other soil properties that are thought to be interrelated.

\section{References}

[1] R. G. Moreno, A. Saa Requejo, A. M. Tarquis Alonso, S. Barrington, and M. C. Díaz, "Shadow analysis: a method for measuring soil surface roughness," Geoderma, vol. 146, no. 12, pp. 201-208, 2008.

[2] R. G. Moreno, M. C. Díaz Álvarez, A. M. Tarquis, A. Paz González, and A. Saa Requejo, "Shadow analysis of soil surface roughness compared to the chain set method and direct measurement of micro-relief," Biogeosciences, vol. 7, no. 8, pp. 2477-2487, 2010.

[3] N. Nunan, K. Ritz, M. Rivers, D. S. Feeney, and I. M. Young, "Investigating microbial micro-habitat structure using X-ray computed tomography," Geoderma, vol. 133, no. 3-4, pp. 398407, 2006.

[4] D. Or, B. F. Smets, J. M. Wraith, A. Dechesne, and S. P. Friedman, "Physical constraints affecting bacterial habitats and activity in unsaturated porous media-a review," Advances in Water Resources, vol. 30, no. 6-7, pp. 1505-1527, 2007.

[5] K. E. Saxton, "Wind erosion and its impact on off-site air quality in the Columbia Plateau - an integrated research plan," Transactions of the American Society of Agricultural Engineers, vol. 38, no. 4, pp. 1031-1038, 1995.

[6] L. J. Cihacek, M. D. Sweeney, and E. J. Deibert, "Characterization of wind erosion sediments in the red river valley of North Dakota," Journal of Environmental Quality, vol. 22, no. 2, pp. 305-310, 1993.

[7] R. Röhrig, M. Langmaack, S. Schrader, and O. Larink, “Tillage systems and soil compaction-their impact on abundance and vertical distribution of Enchytraeidae," Soil and Tillage Research, vol. 46, no. 1-2, pp. 117-127, 1998.

[8] M. Kutílek and L. Jendele, "The structural porosity in soil hydraulic functions-a review," Soil and Water Research, vol. 3, supplement 1, pp. S7-S20, 2008.

[9] A. R. Dexter, "Soil physical quality: part I. Theory, effects of soil texture, density, and organic matter, and effects on root growth," Geoderma, vol. 120, no. 3-4, pp. 201-214, 2004.

[10] A. R. Dexter, E. A. Czyz, G. Richard, and A. Reszkowska, "A user-friendly water retention function that takes account of the textural and structural pore spaces in soil," Geoderma, vol. 143, no. 3-4, pp. 243-253, 2008.

[11] A. Papadopoulos, N. R. A. Bird, A. P. Whitmore, and S. J. Mooney, "Investigating the effects of organic and conventional management on soil aggregate stability using X-ray computed tomography," European Journal of Soil Science, vol. 60, no. 3, pp. 360-368, 2009.

[12] I. M. Young, J. W. Crawford, and C. Rappoldt, "New methods and models for characterising structural heterogeneity of soil," Soil and Tillage Research, vol. 61, no. 1-2, pp. 33-45, 2001.

[13] J. W. Crawford, J. A. Harris, K. Ritz, and I. M. Young, "Towards an evolutionary ecology of life in soil," Trends in Ecology and Evolution, vol. 20, no. 2, pp. 81-87, 2005.

[14] J. M. Oades, "The role of biology in the formation, stabilization and degradation of soil structure," Geoderma, vol. 56, no. 1-4, pp. 377-400, 1993.

[15] F. J. Larney, A. J. Cessna, and M. S. Bullock, "Herbicide transport on wind-eroded sediment," Journal of Environmental Quality, vol. 28, no. 5, pp. 1412-1421, 1999.

[16] A. Hadas, "Long-term tillage practice effects on soil aggregation modes and strength," Soil Science Society of America Journal, vol. 51, no. 1, pp. 191-197, 1987.

[17] A. R. Dexter, "Advances in characterization of soil structure," Soil and Tillage Research, vol. 11, no. 3-4, pp. 199-238, 1988.

[18] C. M. Monreal, M. Schnitzer, H. R. Schulten, C. A. Campbell, and D. W. Anderson, "Soil organic structures in macro and microaggregates of a cultivated Brown Chernozem," Soil Biology and Biochemistry, vol. 27, no. 6, pp. 845-853, 1995.

[19] A. N. Kravchenko, G. P. Robertson, X. Hao, and D. G. Bullock, "Management practice effects on surface total carbon: differences in spatial variability patterns," Agronomy Journal, vol. 98, no. 6, pp. 1559-1568, 2006.

[20] I. M. Young and K. Ritz, "Tillage, habitat space and function of soil microbes," Soil and Tillage Research, vol. 53, no. 3-4, pp. 201-213, 2000.

[21] I. M. Young, J. W. Crawford, N. Nunan, W. Otten, and A. Spiers, "Microbial distribution in soils: physics and scaling," Advances in Agronomy C, vol. 100, pp. 81-121, 2009. 
[22] K. M. Hati, A. Swarup, A. K. Dwivedi, A. K. Misra, and K. K. Bandyopadhyay, "Changes in soil physical properties and organic carbon status at the topsoil horizon of a vertisol of central India after 28 years of continuous cropping, fertilization and manuring," Agriculture, Ecosystems and Environment, vol. 119, no. 1-2, pp. 127-134, 2007.

[23] J. Six, E. T. Elliott, and K. Paustian, "Aggregate and soil organic matter dynamics under conventional and no-tillage systems," Soil Science Society of America Journal, vol. 63, no. 5, pp. 13501358, 1999.

[24] N. G. Juma, "Interrelationships between soil structure/texture, soil biota/soil organic matter and crop production," Geoderma, vol. 57, no. 1-2, pp. 3-30, 1993.

[25] M. Deurer, D. Grinev, I. Young, B. E. Clothier, and K. Müller, "The impact of soil carbon management on soil macropore structure: a comparison of two apple orchard systems in New Zealand," European Journal of Soil Science, vol. 60, no. 6, pp. 945-955, 2009.

[26] M. Feser, J. Gelb, H. Chang et al., "Sub-micron resolution CT for failure analysis and process development," Measurement Science and Technology, vol. 19, no. 9, Article ID 094001, 2008.

[27] J. F. Darbyshire, S. J. Chapman, M. V. Cheshire et al., "Methods for the study of interrelationships between micro-organisms and soil structure," Geoderma, vol. 56, no. 1-4, pp. 3-23, 1993.

[28] J. M. Blair, R. E. Falconer, A. C. Milne, I. M. Young, and J. W. Crawford, "Modeling three-dimensional microstructure in heterogeneous media," Soil Science Society of America Journal, vol. 71, no. 6, pp. 1807-1812, 2007.

[29] S. de Gryze, L. Jassogne, J. Six, H. Bossuyt, M. Wevers, and R. Merckx, "Pore structure changes during decomposition of fresh residue: X-ray tomography analyses," Geoderma, vol. 134, no. 1-2, pp. 82-96, 2006.

[30] B. W. Hapke, "A theoretical photometric function for the lunar surface," Journal of Geophysical Research, vol. 68, pp. 45714586, 1963.

[31] R. F. Isbell, The Australian Soil Classification, Revised Edition, CSIRO, Canberra, Australia, 2002.

[32] Bureau of Meteorology, Australian Government, http://www .bom.gov.au/, 2010. 

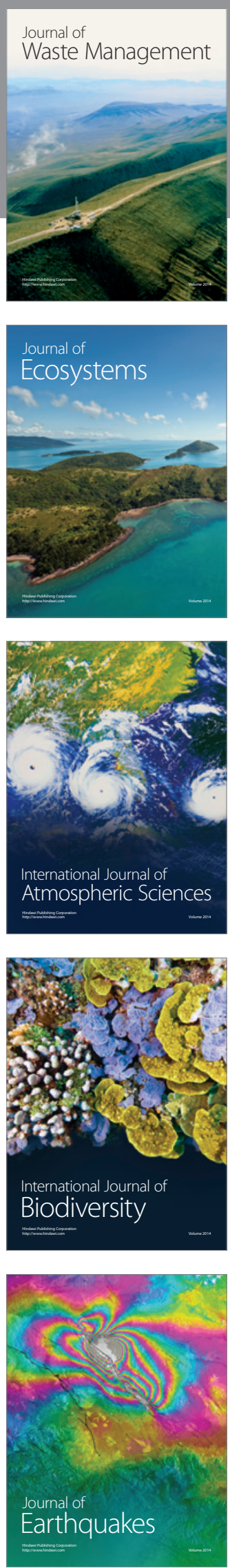


Submit your manuscripts at

http://www.hindawi.com
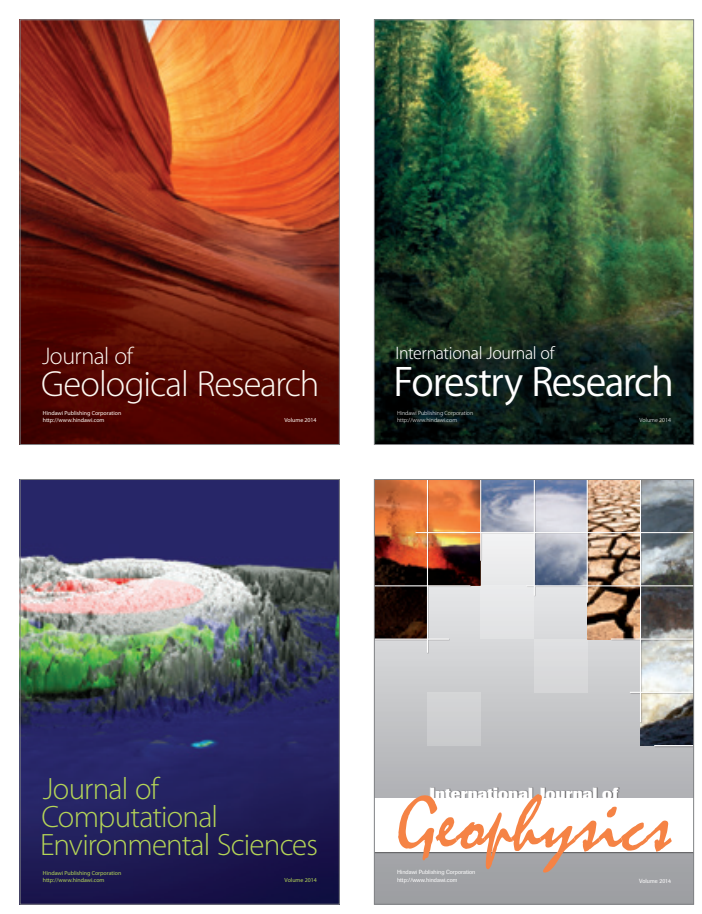
